\title{
Schlaganfall und Herzinfarkt unter der "Pille"?
}

Es gibt viele Studien, die zweifelsfrei nahelegen, dass die Einnahme von oralen Kontrazeptiva das Risiko von venösen Thromboembolien erhöht. Die Datenlage zu thrombotischen Schlaganfällen und Myokardinfarkten ist allerdings weitaus kontroverser. Eine dänische Arbeitsgruppe wollte daher untersuchen, ob es einen Zusammenhang zwischen hormonellen Kontrazeptiva und der Häufigkeit von ischämischen Insulten und Myokardinfarkten gibt.

- Ausgewertet wurde das nationale Patientenregister von Dänemark. Eingeschlossen wurden Frauen im Alter zwischen 15 und 49 Jahren im Zeitraum zwischen Januar 1995 und Dezember 2009. Erfasst wurden alle Erstereignisse im Rahmen dieses Registers, nämlich ischämische Schlaganfälle und Myokardinfarkte. Über das nationale Register für verschreibungspflichtige Medikamente konnte erfasst werden, ob die Frauen hormonelle Kontrazeptiva benutzten und über welchen Zeitraum hinweg.

Insgesamt lagen Daten von 1626158 Frauen mit insgesamt über 14 Millionen Personenjahren vor. In dieser Zeit traten 3311 thrombotische Schlaganfälle und 1725 Myokardinfarkte auf. Die Sterblichkeit bei den Schlaganfällen betrug $1 \%$ und bei den Myokardinfarkten $10,8 \%$. Erwartungsgemäß ergab sich eine Zunahme der Schlaganfall- und Myokardinfarktrate mit dem Alter.

In der Gruppe der Frauen, die hormonelle Kontrazeptiva benutzten, erlitten 1051 Frauen einen Schlaganfall und

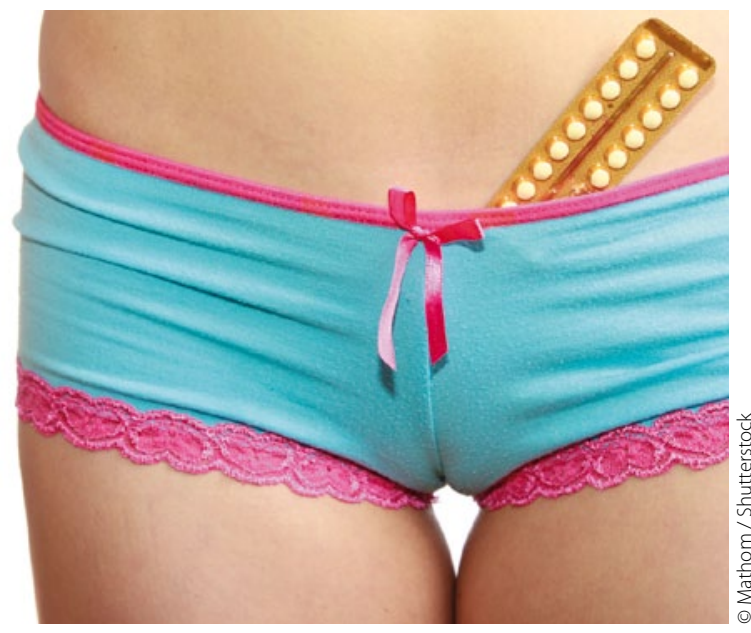

Orale Kontrazeptiva: Risiko gering.
497 einen Myokardinfarkt. Dies entspricht 21,4 und 10,1 pro 100000 Personenjahre. Bei den Frauen die keine hormonelle Kontrazeption erhielten, erlitten 2260 einen Schlaganfall und 1228 einen Myokardinfarkt. Die Inzidenzraten betragen 24,2 und 13,2 pro 100000 Personenjahre. Für hohe Dosen von Estradiol war das Risiko eines thrombotischen Schlaganfalls um den Faktor 2 und das Risiko eines Myokardinfarkts um den Faktor 4 erhöht. Für niedrige Estradioldosen bestand nur ein marginal erhöhtes Risiko. Progestin erhöhte weder das Schlaganfall- noch das Herzinfarktrisiko.

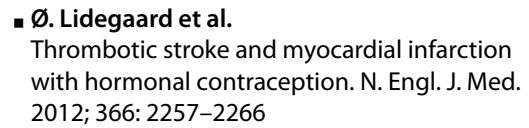

\section{Kommentar}

Diese riesige Studie aus Dänemark ist sehr wichtig, da sie zeigt, dass die Anwendung von hormonellen Kontrazeptiva das Risiko eines ischämischen Insults oder Myokardinfarkts erfreulicherweise nur gering erhöht. Progesteronhaltige hormonelle Kontrazeptiva erhöhen das Risiko nicht. Insgesamt hängt das Risiko von der Estradiolkonzentration ab. Da in den letzten zehn Jahren fast ausschließlich Substanzen mit niedrigen Östrogendosierungen verwendet werden, ist daher das Schlaganfall- und Myokardinfarktrisiko unter hormoneller Kontrazeption weitestgehend zu vernachlässigen. Die Studie zeigt auch, wie wertvoll es ist, wenn Krankheiten, Diagnosen und verschriebene Medikamente in großen Registern zusammengeführt werden. Ein solches Register wie in Dänemark wäre aber für jeden Datenschützer in Deutschland ein Alptraum.

H.-C. DIENER = 